\title{
Experiences of Laparoscopic Partial Nephrectomy for T1a Kidney Tumours: Results of Two Hundred and Fifteen Patients
}

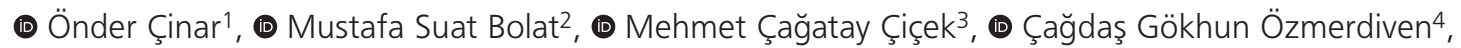 \\ (-) Berna Aytaç Vuruşkan5, (0 Hakan Vuruşkan ${ }^{3}$ \\ 1 Zonguldak Bülent Ecevit University, Health Application and Research Center, Department of Urology, Zonguldak, Turkey \\ 2 Samsun Gazi State Hospital, Clinic of Urology, Samsun, Turkey \\ ${ }^{3}$ Bursa Uludağ University Faculty of Medicine, Department of Urology, Bursa, Turkey \\ 4 Istanbul Aydin University Faculty of Medicine, Department of Urology, Istanbul, Turkey \\ ${ }^{5}$ Bursa Uludağ University Faculty of Medicine, Department of Pathology, Bursa, Turkey
}

\begin{abstract}
Objective: The best therapeutic option for renal tumours smaller than $7 \mathrm{~cm}$ is partial nephrectomy. The aim of this study was to compare the positive surgical margin (PSM) rates, recurrence rates and oncological outcomes between laparoscopic partial nephrectomies and open partial nephrectomies at a single tertiary referral centre.

Materials and Methods: We included patients with renal tumours treated with partial nephrectomies between January 2008 and December 2016 in the study. We retrospectively reviewed the patients' demographic data, surgical reports, clinical charts, laboratory results and histopathological reports. Binary regression analysis was used to assess the impact of the tumour diameter, laterality, polarity and localization for PSM.

Results: We included a total of 215 patients in the study. The mean preoperative and postoperative haemoglobin and creatinine levels, blood loss, time of surgery and follow-up periods was similar between the two groups. The mean ischaemic time in the open partial nephrectomy group was significantly lower than that of the laparoscopic partial nephrectomy group $(p<0.05)$. Local recurrence was seen in a patient with a PSM in the laparoscopic partial nephrectomy group. However, recurrences were also seen in the negative surgical margin patients in both the open partial nephrectomy and laparoscopic partial nephrectomy groups.

Conclusion: The presence of a PSM is not associated with an increased risk of distant metastases or local recurrences. However, higher PSM rates were associated with the early learning curve for a laparoscopic procedure. Finally, an open partial nephrectomy is associated with shorter warm ischaemia time compared to laparoscopic partial nephrectomy group.
\end{abstract}

Keywords: Distant metastasis, kidney tumour, local recurrence, partial nephrectomy, surgical margin positivity

\section{Introduction}

The best therapeutic option for localized renal tumours is surgical removal amongst other therapeutic options (1). As a standard treatment option, a partial nephrectomy (PN) provides better oncological and functional results for T1 renal tumours $(\leq 7 \mathrm{~cm})$; with the advantage of healthy renal parenchyma preservation $(1,2)$. An open PN $(\mathrm{OPN})$ has been a safe technique for many years, with high cancer-free survival rates, a better quality of life results, and low local recurrence rates (3). Due to, OPN technique requires longer hospitalisation rates, the need for longer surgical incisions, higher analgesic requirements and an increased comorbidity rate, minimally invasive techniques have become more popular. Advancements in minimally invasive procedures have increased the potential for laparoscopic and robot-assisted PNs, increasing the number of nephron sparing surgeries for $\mathrm{T} 1$ tumours. The evolution of imaging techniques (4) have led to the diagnosis of asymtomatic renal masses (up to $27 \%)$, with an risk of residual tumours $(0.1 \%-10.7 \%)(5,6)$. The surgical technique applied, the skill of the surgeon, and tumour characteristics, such as the location, stage, and grade determines the recurrence rate of the tumour $(5,7)$. No matter the technique, the main goal of a successful tumour management is to remove the renal tumour completely, with lower warm ischaemia times (WITs) (8) and minimal postoperative complication rates (9).

Cite this article as: Çinar Ö, Bolat MS, Çiçek MÇ, Özmerdiven ÇG, Vuruşkan AV, Vuruşkan H. Experiences of Laparoscopic Partial Nephrectomy for T1a Kidney Tumours: Results of Two Hundred and Fifteen Patients. Bull Urooncol 2020;19(3):130-135

Address for Correspondence: Önder Çinar, Zonguldak Bülent Ecevit University, Health Application and Research Center, Department of Urology, Zonguldak, Turkey Phone: +90 5059504311 E-mail: drondercinar@gmail.com ORCID-ID: orcid.org/0000-0002-0107-5843 
In this study, the positive surgical margin (PSM) rates mean ischaemic times, perioperative complication rates, and associated risk factors were compared between OPNs and laparoscopic partial nephrectomies (LPNs) in patients undergoing PNs for kidney tumours.

\section{Materials and Methods}

After obtaining Institutional Board Approval from the Clinical Research and Ethics Committee of Zonguldak Bülent Ecevit University (Zonguldak, Turkey) (approval number: 2019-9412/06, date: 12.06.2019). We then retrospectively reviewed the data of 315 patients with kidney tumours who had undergone LPNs or OPNs, done in a high volume experienced centre between January 2008 and December 2016. We excluded patients with bilateral kidney tumours $(n=16)$ and with a less than two year follow-up $(n=14)$ from the study. Seventy patients with tumours higher than $7 \mathrm{~cm}$, with lymph nodes or distant metastases, and with a history of PNs for benign diseases of the kidney were also excluded from the study.

Finally, the preoperative and postoperative data from 215 patients with complete data were evaluated. The demographic, surgical reports, clinical charts, laboratory results and histopathological reports were reviewed. In addition, detailed medical histories and physical examination findings were obtained in all of the cases.

Patients with T1 kidney tumours were divided into two groups according to the applied surgical technique: an OPN group (group 1, n=46) and an LPN group (group 2, n=169). We assessed the recurrence using radiological methods and additional histopathological examinations where needed. The cancer recurrences were clinically or radiologically assessed in both groups. The presence of a contralateral non-functional kidney or the presence of a tumour in an anatomically solitary kidney was accepted as imperative indications for a PN. The LPN criteria were based on the computed tomography (CT) findings, including the size, localization, and accessibility of the mass, in addition to the general health status and comorbidities of the patient.

\section{Surgical Procedure}

The LPN procedure was performed transperitoneally with the patient in a lateral decubitus position. A $12 \mathrm{~mm}$ optical camera port was inserted $5 \mathrm{~cm}$ lateral at the level of the umbilicus after the pneumoperitoneum was created using a Veress needle. The $10 \mathrm{~mm}$ subxiphoidal trocar and $5 \mathrm{~mm}$ trocar were placed approximately $2 \mathrm{~cm}$ medially and superior to the anterior superior iliac crest to create a triangularly shape under direct vision. For tumours on the right side, an additional $5 \mathrm{~mm}$ port was used to retract the liver. The colon was then mobilised medially, and the renal vascular pedicle was exposed. The main renal artery was clamped using a bulldog clamp and the tumour was resected within a safe margin, and put into an endo bag. The renal parenchyma was sutured using 2-0 monofilament poliglecaprone (Monocryl®, Ethicon) sutures in a running manner.
For the OPN, a flank incision was made in patients with lower pole kidney tumours. A subcostal approach was used for those who had upper pole or middle tumours. The renal artery was clamped and the resection of the tumour with the surrounding normal parenchyma was completed and figure eight knots were used for closing the collecting system and the renorrhaphy.

\section{The follow-up protocol was defined as follows:}

1. Complete physical examinations and serum creatinine measurements were done at the postoperative first, third and twelfth months and annually thereafter.

2. Plain chest $X$-rays and CT scans of the abdomen were obtained in the sixth postoperative month and annually after that.

\section{Histopathological Investigation}

All the PN specimens were evaluated by the same pathologist. Tumour grading and pathological staging were done according to the Fuhrman et al. (10) nuclear grading system and the 2016 World Health Organization classification (11). The presence of malignant cells at the surgical margin was defined as surgical margin positivity.

\section{Statistical Analysis}

The demographic variables, including age, gender and indication for surgery, laterality, diameter and location of the tumour was assessed. The mean follow-up periods, histopathological diagnoses, tumour grades and recurrence rates of the groups were compared using IBM SPSS Statistics for Windows, version 22.0 (IBM Corp., Armonk, NY, USA). An Independent Sample t-test and chi-squared test was used to compare the variables and ratios between the two groups. A p value of less than 0.05 was considered statistically significant. Binary regression analysis was performed to assess the impact of the tumor diameter, laterality, polarity and localization for PSM.

\section{Results}

The demographic and clinical characteristics of the LPN and OPN groups, including the age, body mass index, gender, glomerular filtration rate, American Society of Anaesthesiologists score, and comorbidity, presence of surgical margin positivity, tumour location and diameter are given in Table 1. The mean preoperative and postoperative haemoglobin, blood loss, and creatinine levels and the mean surgical time and follow-up periods were similar between the groups $(p>0.05)$. The mean warm ischaemia time in the OPN group was significantly lower when compared to the LPN group $(p<0.05)$. Other variables, such as the recurrence rate and the clinical and histopathological findings are shown in Table 2.

One patient with a surgical margin positivity in the LPN group had local recurrence. One patient in the OPN group with negative surgical margins (NSMs) and two patients (1.2\%) in the LPN group with NSMs had local recurrences within a mean follow-up period of 29.8 months. Two patients in the LPN group with NSMs (1.2\%) had bone and lung distant metastases in the $19^{\text {th }}$ and $54^{\text {th }}$ months. The overall recurrence or metastasis rate was $2.8 \%$. 
Binary logistic regression analysis was performed to assess the impact of the tumor diameter, laterality, polarity and localization for PSM $(p>0.05)$. The individual characteristics of the patients with recurrences or metastases following the PNs are given in Table 3. Three of the patients had recurrence in the LPN group with Fuhrman grade 3, and two had Fuhrman grade 2 tumours.

\begin{tabular}{|c|c|c|c|}
\hline & $\begin{array}{l}\text { OPN group } \\
(n=46)\end{array}$ & $\begin{array}{l}\text { LPN group } \\
(n=169)\end{array}$ & $\mathrm{p}$ \\
\hline Age (years), (mean $\left.\pm S D^{1}\right)$ & $54.7 \pm 12.1$ & $55.9 \pm 11.9$ & 0.87 \\
\hline $\mathrm{BMI}^{2}\left(\mathrm{~kg} / \mathrm{m}^{2}\right),($ mean $\pm \mathrm{SD})$ & $27.3 \pm 4.1$ & $26.8 \pm 3.7$ & 0.89 \\
\hline \multicolumn{4}{|l|}{ Gender } \\
\hline Male & 22 & 79 & \multirow{2}{*}{ - } \\
\hline Female & 24 & 90 & \\
\hline \multicolumn{4}{|l|}{ ASA $^{3}$ Score } \\
\hline 1 & 25 & 96 & \multirow{4}{*}{ - } \\
\hline II & 17 & 56 & \\
\hline III & 4 & 15 & \\
\hline IV & 0 & 2 & \\
\hline $\mathrm{GFR}^{4}\left(\mathrm{~mL} / \mathrm{min} \times 1.73 \mathrm{~m}^{2}\right)$ & $91.3 \pm 23.2$ & $92 \pm 22.4$ & 0.85 \\
\hline \multicolumn{4}{|l|}{ Comorbidity } \\
\hline Hypertension & 16 & 37 & \multirow{3}{*}{-} \\
\hline Diabetes Mellitus & 11 & 17 & \\
\hline Past surgery & 17 & 62 & \\
\hline \multicolumn{4}{|l|}{ Symptom } \\
\hline No & 28 & 109 & \multirow{5}{*}{-} \\
\hline Haematuria & 2 & 3 & \\
\hline Pain & 13 & 42 & \\
\hline LUTS $^{5}$ & 1 & 10 & \\
\hline Nonspecific & 2 & 5 & \\
\hline Tumour diameter (mm) & $35.3 \pm 12.9$ & $30.1 \pm 10.8$ & 0.15 \\
\hline \multicolumn{4}{|l|}{ Tumour localization } \\
\hline Right kidney & 27 & 98 & \multirow{11}{*}{ - } \\
\hline Left kidney & 19 & 71 & \\
\hline Anterior & 32 & 120 & \\
\hline Posterior & 14 & 49 & \\
\hline Upper pole & 14 & 70 & \\
\hline Middle pole & 9 & 53 & \\
\hline Lower pole & 23 & 46 & \\
\hline Exophytic & 41 & 153 & \\
\hline Endophytic & 5 & 16 & \\
\hline Lateral rim & 37 & 136 & \\
\hline Medial rim & 9 & 33 & \\
\hline \multicolumn{4}{|l|}{ Surgical margin (n, \%) } \\
\hline Positive & $3(6.5)$ & $13(7.7)$ & 0.91 \\
\hline Negative & $43(93.5)$ & $153(92.3)$ & 0.89 \\
\hline
\end{tabular}

\section{Discussion}

PN has become the standard surgical method for the treatment of T1 renal tumours with similar oncological results; however, there are still debates with regards to its relationship with PSMs and local recurrences. Our results showed that the tumor diameter, laterality, polarity and localization were not associated with PSM. Kwon et al. (12) showed that local recurrence after a PN was related to the high malignant potential of the tumour and the presence of a PSM. Irrespective of the tumour complexity, a PSM was found to be associated with a higher Nephrometry score, the presence of bilateral tumours, a prior renal cell carcinoma treatment history, local recurrence and distant metastasis when compared to patients with NSMs (13). On the contrary, many institutional data have shown that the surgical margin status did not influence the tumour recurrence risk in pT1 tumours after a PN (14). In a comparative meta-analytical study analyzing the data of 45,786 patients, a larger tumour size, a pT3a stage, nuclear grade 3-4 and minimally invasive procedures, were found to be potential risk factors for a local recurrence. However, cancer-specific and overall survival rates were not increased by the use of minimally invasive procedures (15). Our results showed that local recurrence was observed only in one patient with a PSM in the LPN group, a very low number of patients with NSM showed that there was no association with surgical margin positivity and local recurrence or distant metastasis in both groups. Two of the patients in the LPN group had bone and lung metastasis respectively. One of the patients with distant metastasis had a tumour necrosis (Fuhrman grade 3) and the other had a relatively endophytic mass close to the collection system with microvascular invasion. Histopathological and morphological findings such as high tumour grade and endophytic location of the tumour, may explain the distant metastases in our patients with NSM as reported earlier.

In this study, three patients (6.5\%) in the OPN group showed PSM with no local recurrence. Although only a patient in the OPN group and two patients in the LPN group had local recurrence, no difference was observed in cancer-specific or overall survival which is consistent with the literature (16). A previous cohort study of 11,587 patients, showed that the PSM rates were $4.9 \%, 8.7 \%$ and $8.1 \%$ for open, robotic and laparoscopic PNs respectively (17). Considering PSM ratios, our results in the OPN group were similar to those of the previously published reports, which may be attributed to the cumulative skills of the urologists in open surgery. The $7.7 \%$ PSM rate recorded for the LPN group was similar to that found in literature. However, when a detailed analysis was done, the PSM rate was the highest for the first 50 cases $(10.0 \%)$, and it decreased to a rate of $8 \%$ for the second 50 cases. As previously reported, this can be explained by the need for more complex skills and a relatively long learning curve (18). Consistent with literature, the PSM ratio was only $4.3 \%$ in the last 69 patients in the LPN group (19).

Nevertheless, the primary goal should be not to leave a PSM during a PN (7). A healthy parenchymal margin of $1 \mathrm{~cm}$ has been suggested for optimal cancer control $(20,21)$. Due to the likelihood of a PSM, challenging cases require close followups and careful surveillance and salvage procedures should 


\begin{tabular}{|c|c|c|c|c|c|}
\hline & \multicolumn{2}{|l|}{ OPN group $(n=46)$} & \multicolumn{2}{|l|}{ LPN group $(n=169)$} & \multirow[b]{2}{*}{$\mathbf{p}$} \\
\hline & $\mathrm{PSM}^{*}(\mathrm{n}=3)$ & $\mathrm{NSM}^{* *}(\mathrm{n}=43)$ & $\operatorname{PSM}(n=13)$ & NSM $(n=156)$ & \\
\hline \multicolumn{6}{|l|}{ Haemoglobin $\left(\mathrm{g} / \mathrm{dL}\right.$, mean $\left.\pm \mathrm{SD}^{* * *}\right)$} \\
\hline Preoperative & $12.8 \pm 2.3$ & $13.2 \pm 1.8$ & $13.5 \pm 1.3$ & $13.2 \pm 1.6$ & 0.66 \\
\hline Postoperative & $11.6 \pm 2.3$ & $11.8 \pm 2.3$ & $12.4 \pm 1.6$ & $12.0 \pm 1.1$ & 0.65 \\
\hline \multicolumn{6}{|l|}{ Serum creatinine $(\mathrm{mg} / \mathrm{dL}$, mean $\pm \mathrm{SD})$} \\
\hline Preoperative & $0.8 \pm 0.1$ & $0.9 \pm 0.3$ & $0.9 \pm 0.2$ & $0.8 \pm 0.2$ & 0.39 \\
\hline Postoperative & $0.7 \pm 0.2$ & $1.1 \pm 0.4$ & $0.9 \pm 0.3$ & $1.0 \pm 0.3$ & 0.10 \\
\hline Warm ischaemia time (min, mean \pm SD) & $10.5 \pm 8.0$ & $18.8 \pm 8.3$ & $21.2 \pm 9.0$ & $21.3 \pm 8.9$ & 0.02 \\
\hline Surgery time (min, mean \pm SD) & $160.6 \pm 67.4$ & $161.4 \pm 69.6$ & $156.8 \pm 75.2$ & $136.8 \pm 71.1$ & 0.95 \\
\hline Non-klemp (n) & 1 & 1 & 2 & 7 & - \\
\hline \multicolumn{6}{|l|}{ Surgical technique (n) } \\
\hline Retroperitoneal & 0 & 8 & 1 & 11 & - \\
\hline Transperitoneal & 3 & 35 & 12 & 145 & - \\
\hline Blood loss $(\mathrm{mL}$, mean $\pm \mathrm{SD})$ & $125.0 \pm 35.4$ & $137.1 \pm 127.0$ & $138.7 \pm 43.5$ & $139.6 \pm 52.9$ & 0.89 \\
\hline Follow-up (months, mean \pm SD) (minimum-maximum) & $44.8 \pm 13.5(29-62)$ & $45.6 \pm 18.8(25-90)$ & $46.5 \pm 32.4(25-147)$ & $40.6 \pm 18.7(25-137)$ & 0.93 \\
\hline Local recurrence $(n, \%)$ & 0 & $1(2.2)$ & 1 & $2(1.2)$ & - \\
\hline Distant metastasis (n, \%) & - & - & - & $2(1.2)$ & - \\
\hline Time to local recurrence (month mean \pm SD) & 0 & 29 & 3 & 29.8 & - \\
\hline \multicolumn{6}{|l|}{ Histology (n, \%) } \\
\hline Clear cell & $2(4.3)$ & $26(56.5)$ & $8(4.7)$ & $111(65.7)$ & \multirow{4}{*}{ - } \\
\hline Papillary & $1(2.2)$ & $10(21.7)$ & $3(1.8)$ & $24(14.2)$ & \\
\hline Chromophobe & 0 & $4(8.7)$ & $1(0.6)$ & $12(7.1)$ & \\
\hline Other & 0 & $3(6.5)$ & $1(0.6)$ & $9(5.3)$ & \\
\hline \multicolumn{6}{|l|}{ Pathological stage (n, \%) } \\
\hline T1a & 3 & 35 & 9 & 131 & \multirow[b]{2}{*}{ - } \\
\hline T1b & 0 & 8 & 4 & 25 & \\
\hline \multicolumn{6}{|l|}{ Pathological grade (Fuhrman) } \\
\hline Grade 1 & 0 & 8 & 1 & 35 & \multirow{3}{*}{-} \\
\hline Grade 2 & 3 & 21 & 5 & 71 & \\
\hline Grade 3 & 0 & 14 & 7 & 50 & \\
\hline Presence of tumour necrosis (n, \%) & 0 & $2(4.3)$ & $1(0.6)$ & $10(5.6)$ & - \\
\hline Invasion to collecting system (n, \%) & - & - & - & - & - \\
\hline Pernephric infiltration (n, \%) & - & - & - & $3(1.8)$ & - \\
\hline Vascular invasion (n, \%) & - & - & - & - & - \\
\hline
\end{tabular}

\begin{tabular}{|c|c|c|c|c|c|c|c|c|}
\hline Age & Grouping & Tumour type & $\begin{array}{l}\text { Fuhrman } \\
\text { grade }\end{array}$ & $\begin{array}{l}\text { Largest } \\
\text { tumour size }(\mathrm{mm})\end{array}$ & $\begin{array}{l}\text { Surgical } \\
\text { margin }\end{array}$ & $\begin{array}{l}\text { Time to } \\
\text { recurrence (months) }\end{array}$ & $\begin{array}{l}\text { Local } \\
\text { recurrence }\end{array}$ & $\begin{array}{l}\text { Site of } \\
\text { metastasis }\end{array}$ \\
\hline 59 & LPN & Clear cell & 2 & 35 & - & 54 & - & Bone \\
\hline 72 & LPN & Clear cell & 3 & 12 & - & 19 & - & Lung \\
\hline 71 & OPN & Papillary & 3 & 40 & - & 29 & Ipsilateral kidney & - \\
\hline 42 & LPN & Papillary & 3 & 42 & - & 2 & Ipsilateral kidney & - \\
\hline 73 & LPN & Clear cell & 2 & 35 & + & 3 & Ipsilateral kidney & - \\
\hline
\end{tabular}


be reserved for patients with locally advanced or high-grade tumours.

Only two of our patients showed distant metastases in the LPN cases with NSM, but no metastasis was observed in the participants in the OPN group or the LPN patients with PSM. At first glance, although the absence of metastasis in PSM seemed unreasonable, as previously reported, distant metastasis was not only related to the presence of PSM, but also tumour grade, subtype, microvascular invasion, necrosis and tumoural invasion to the collecting system (22).

The WIT is an essential parameter for postoperative kidney function (23). Studies have shown that a lower WIT was associated with better kidney function postoperatively (9). When compared to an OPN, a longer WIT is expected for an LPN (24). This study's result showed that the mean WIT values were significantly less than 25 minutes, particularly in the OPN group.

\section{Study Limitations}

Oncological outcomes and PSM rates between LPNs and open partial nephrectomies at a single tertiary referral centre were compared in this study. This study had some limitations including;

1. Lack of a long-term follow-up period

2. The retrospective design of the study

3. Many studies have been done in literature about surgical margin positivity.

\section{Conclusions}

The presence of a PSM, although considered to be a risk factor for distant metastasis, was not associated with an increased risk of distant metastasis in this study. Nevertheless, the early stages of the learning curve for an LPN may be associated with higher PSM rates, and this may be a risk factor for distant metastases when combined with other histological and morphological features, such as the nuclear grade of the tumour, the presence of necrosis and endophytic localization.

\section{Acknowledgements}

Publication: This study was presented in the $14^{\text {th }}$ International Urooncology Congress on November 6-10 in 2019, Antalya.

Contribution: There is not any contributors who may not be listed as authors.

Conflict of Interest: No conflict of interest was declared by the authors.

Financial Disclosure: The authors declared that this study received no financial support.

\section{Ethics}

Ethics Committee Approval: After obtaining Institutional Board Approval from the Clinical Research and Ethics Committee of Zonguldak Bülent Ecevit University (Zonguldak, Turkey) (approval number: 2019-94-12/06, date: 12.06.2019).

Informed Consent: Retrospective study.
Peer-review: Internally and externally peer-reviewed.

\section{Authorship Contributions}

Supervision: H.V., Concept Ö.Ç., Design: Ö.Ç., M.Ç.Ç., Ç.G.Ö., Data Collection or Processing: M.Ç.Ç., Ç.G.Ö., B.A.V., Analysis or Interpretation: Ö.Ç., Literature Search: M.S.B., Writing: Ö.Ç.

\section{References}

1. Ljungberg $B$, Bensalah $K$, Canfield $S$, et al. EAU guidelines on renal cell carcinoma: 2014 update. Eur Urol 2015;67:913-924.

2. Campbell SC, Novick AC, Belldegrun A, et al. Guideline for management of clinical T1 renal mass. J Urol 2009;182:1271-1279.

3. Ghavamian R, Cheville JC, Lohse CM, et al. Renal cell carcinoma in the solitary kidney: an analysis of complications and outcome after nephron sparing surgery. J Urol 2002;168:454-459.

4. Gill IS, Aron M, Gervais DA, Jewett MA. Clinical practice. Small renal mass. N Engl J Med 2010;362:624-634.

5. Laganosky DD, Filson CP, Master VA. Surgical margins in nephronsparing surgery for renal cell carcinoma. Curr Urol Rep 2017;19:8.

6. Power NE, Silberstein JL, Touijer K. Is laparoscopic partial nephrectomy already the gold standart for small renal masses? Arch Esp Urol 2013;66:90-98.

7. Hermanek P, Wittekind C. The pathologist and the residual tumor (R) classification. Pathol Res Pract 1994;190:115-123.

8. Khalifeh A, Autorino R, Hillyer SP, et al. Comparative outcomes and assessment of Trifecta in 500 robotic and laparoscopic partialnephrectomy cases: a single surgeon experience. J Urol 189:1236-1242.

9. Hung AJ, Cai J, Simmons MN, Gill IS. "Trifecta" in partial nephrectomy. J Urol 2013;189:36-42.

10. Fuhrman SA, Lasky LC, Limas C. Prognostic significance of morphologic parameters in renal cell carcinoma. Am J Surg Pathol 1982;6:655-663.

11. Moch H, Cubilla AL, Humphrey PA, et al. The 2016 WHO Classification of Tumours of the Urinary System and Male Genital Organs-Part A: Renal, Penile, and Testicular Tumours. Eur Urol 2016;70:93-105.

12. Kwon EO, Carver BS, Snyder ME, Russo P. Impact of positive surgical margins in patients undergoing partial nephrectomy for renal cortical tumours. BJU Int 2007;99:286-289.

13. Petros FG, Metcalfe MJ, Yu KJ, et al. Oncologic outcomes of patients with positive surgical margin after partial nephrectomy: a 25-year single institution experience. World J Urol 2018;36:1093-1101.

14. Kang HW, Lee SK, Kim WT, et al. Surgical margin does not influence recurrence rate in pT1 clear cell renal cell carcinoma after partial nephrectomy: A multicenter study. J Surg Oncol 2016;114:70-74.

15. Vincenzoa F, Alessandro C, Inferrera A, et al. Positive Surgical Margins After Partial Nephrectomy: A Systematic Review and Meta-Analysis of Comparative Studies. Kidney Cancer 2018;2:133-145.

16. Salami SS, George AK, Rais-Bahrami S, et al. Off-clamp laparoscopic partial nephrectomy for hilar tumors: oncologic and renal functional outcomes. J Endourol 2014;28:191-195.

17. Tabayoyong W, Abouassaly R, Kiechle JE, et al. Variation in Surgical Margin Status by Surgical Approach among Patients Undergoing Partial Nephrectomy for Small Renal Masses. J Urol 2015; 194:1548-1553.

18. Gozen AS, Gherman V, Akin Y, et al. Evaluation of the complications in laparoscopic retroperitoneal radical nephrectomy; An experience of high volume centre. Arch Ital Urol Androl 2017;31;89:266-271.

19. Chang KD, Abdel Raheem A, Kim KH, et al. Functional and oncological outcomes of open, laparoscopic and robot-assisted partial 
nephrectomy: a multicentre comparative matched-pair analyses with a median of 5 years' follow-up. BJU Int 2018;122:618-626.

20. Sutherland SE, Resnick MI, Maclennan GT, Goldman HB. Does the size of the surgical margin in partial nephrectomy for renal cell cancer really matter? J Urol 167:61-64.

21. Russo P. Renal cell carcinoma: presentation, staging, and surgical treatment. Semin oncol 2000;27:160-176.

22. Sun M, Shariat SF, Cheng C, et al. Prognostic factors and predictive models in renal cell carcinoma: a contemporary review. Eur Urol 2011;60:644-661.
23. Springer C, Hoda MR, Fajkovic $H$, et al. Laparoscopic vs open partial nephrectomy for $\mathrm{T} 1$ renal tumours: evaluation of longterm oncological and functional outcomes in 340 patients. BJU Int 2013;111:281-288.

24. Minervini A, Siena G, Antonelli A, et al. Open versus laparoscopic partial nephrectomy for clinical T1a renal masses: a matched-pair comparison of 280 patients with TRIFECTA outcomes (RECORd Project.). World J Urol 2014;32:257-263. 